Western University

Scholarship@Western

Education Publications

Education Faculty

2016

Direct and Indirect Forms of Childhood Maltreatment and Nonsuicidal-Self-Injury Among Clinically-Referred Children and Youth

Jenna Armiento

Western University

Cloe Hamza

Western University

Shannon Stewart

Western University

Alan Leschied

Western University

Follow this and additional works at: https://ir.lib.uwo.ca/edupub

Part of the Education Commons, and the Psychology Commons

Citation of this paper:

Armiento, Jenna; Hamza, Cloe; Stewart, Shannon; and Leschied, Alan, "Direct and Indirect Forms of Childhood Maltreatment and Nonsuicidal-Self-Injury Among Clinically-Referred Children and Youth" (2016). Education Publications. 33.

https://ir.lib.uwo.ca/edupub/33 
Direct and indirect forms of childhood maltreatment and nonsuicidal-self-injury among

\author{
clinically-referred children and youth \\ Jenna Armiento, MA* \\ Chloe Hamza, Ph.D.* \\ Shannon L. Stewart, Ph.D* \\ Alan Leschied, Ph.D.*
}

* Faculty of Education, Western University, 1137 Western Road, London ON Canada, N6G 1G7

All four authors contributed to the conception and design of the work, the analysis and interpretation of data, the editing and writing of the work, and approved the final work for submission. All authors are accountable for this work and its accuracy.

No authors have any conflicts of interest to declare.

Correspondence regarding this paper should be directed to Jenna Armiento, Faculty of Education, Western University, 1137 Western Road, London ON Canada, N6G1G7 or by email at: jarmient@uwo.ca 


\section{At a Glance}

- This paper examined childhood maltreatment as a risk factor for nonsuicidal self-injury (NSSI) among a clinical sample of children and youth while including the largely neglected area of indirect forms of maltreatment such as exposure to intimate partner violence.

- Univariate analyses demonstrated positive associations with NSSI and both direct (i.e., physical, sexual) and indirect child maltreatment (i.e., exposure to intimate partner violence).

- Multivariate analyses demonstrated that only exposure to intimate partner violence emerged as a predictor of NSSI.

- The present study provides evidence for vicarious trauma as a risk factor for NSSI. 


\section{Abstract}

Importance: Although exposure to direct forms of childhood maltreatment is among the most widely studied risk factors for nonsuicidal self-injury (NSSI), research on NSSI has largely neglected the role of exposure to indirect forms of child maltreatment (i.e., exposure to intimate partner violence).

Objective: To address this gap in the literature, the present study examined associations among both direct and indirect forms of maltreatment and NSSI among clinically referred children and youth. It was expected that exposure to both forms of maltreatment would be associated with increased risk for NSSI engagement.

Design: Data was collected from September 2014 - August 2015 using the interRAI Child and Youth Mental Health Assessment (ChYMH) at ten mental health agencies in Ontario, Canada. The ChYMH is a comprehensive standardized clinical assessment tool completed by trained assessors using multiple sources (e.g., child, parent, clinical charts, observations) at time of patient intake into clinical care.

Setting: Data was collected by trained clinical assessors at both community-based mental health facilities and inpatient/residential treatment facilities in Ontario, Canada.

Participants: The study included a convenience sample of 747 children and youth (68\% male) with complex mental health histories (i.e., impairments in physical, mental, and emotional functioning) referred for inpatient or outpatient care in Ontario, Canada. Participant eligibility criteria included: enrolled in outpatient/inpatient care at one of participating mental health agencies, informed consent from parent and child, verbal fluency in English for both parent and child, and the child or youth was between the ages of 8-18 years.

Main Outcome and Measure: The primary outcome assessed was the presence/absence of NSSI as assessed on the Self-Injury Scale (SOS) on the ChYMH.

Results: Univariate chi-square analyses reflected positive associations with NSSI and both direct (i.e., physical, sexual) and indirect child maltreatment (i.e., exposure to intimate partner violence). In a binary logistic regression analysis controlling for participant age and sex, only exposure to indirect child maltreatment emerged as multivariate predictor of NSSI.

Conclusion and Relevance: The present study provides evidence that experiencing vicarious trauma in childhood is an important risk factor for NSSI. Implications for clinicians include developing targeted intervention and prevention strategies for NSSI among children and youth for children who have witnessed domestic violence in the home. 
Direct and indirect forms of childhood maltreatment and nonsuicidal-self-injury among clinically-referred children and youth

Nonsuicidal self-injury (NSSI) is defined in the Diagnostic and Statistical Manual of Mental Disorders $V$ as direct and deliberate bodily harm in the absence of suicidal intent (American Psychiatric Association, 2013) and includes behaviours such as cutting, scratching of skin, head-banging and biting (Heath, Toste, Nedecheva \& Charlesbois, 2008). NSSI typically emerges between the age of 12 to 15 years, and prevalence rates of lifetime NSSI engagement range from 14-24\% among adolescent community-based samples (Giletta, Burk, Scholte, Engels \& Prinstein, 2012; Muehlenkamp \& Gutierrez, 2004; Ross \& Heath, 2002) and 40\%-60\% among clinical samples (Cloutier, Martin, Kennedy, Nixon \& Muehlenkamp, 2010; Nixon, Cloutier \& Aggarwal, 2002). Although exposure to direct forms of childhood maltreatment (i.e., physical abuse, sexual abuse) is among the most widely studied risk factors for nonsuicidal self-injury (NSSI), research on NSSI has largely neglected the role of exposure to indirect forms of child maltreatment. In particular, researchers have yet to examine whether exposure to intimate partner violence (i.e., an indirect form of child maltreatment) may be associated with an increased risk for NSSI. To address this significant gap in the literature, the present study examined associations among direct maltreatment (i.e., physical, sexual), indirect maltreatment (i.e., exposure to intimate partner violence) and NSSI among a sample of clinically referred children and youth at high risk for recent exposure to childhood maltreatment. Importantly, identifying family factors associated with NSSI engagement, will inform clinical care planning for children and youth.

\section{Childhood Maltreatment}


Childhood maltreatment includes direct forms (e.g., physical, sexual) as well as indirect forms of abuse (e.g., neglect, exposure to domestic violence), and is a prevalent issue that is experienced by many children across North America (Sedlak et al., 2010). In the most recent Canadian Incidence Study of Reported Child Abuse and Neglect (CIS), there were approximately 235,842 reported childhood maltreatment-related incidents investigated in 2008 (Trocmé et al., 2010). These data are only representative of cases reported to child welfare and does not include those reported to police or not reported, suggesting the actual number of incidents of childhood maltreatment in Canada is estimated to be significantly higher. According to the CIS (2008), neglect and exposure to intimate partner violence are the most commonly reported forms of maltreatment experienced by children and youth (34\%), followed by physical abuse (20\%), emotional abuse (9\%) and sexual abuse (3\%).

Childhood maltreatment has been associated with numerous short-term and long-term negative outcomes (Webster, 2013; Hamza, Stewart \& Willoughby, 2012). Children who are maltreated are more likely to develop mental health problems such a depression, anxiety and substance use in young adulthood (Scott et al., 2012; Stewart, Leschied, den Dunnen, Zalmanowitz \& Baiden, 2012). Moreover, it has been determined that previous childhood maltreatment can lead to intrapersonal problems such as decreased self-esteem, as well as increased risk for re-victimization of abuse as an adult (Campbell, Greeson, Bybee \& Raya, 2008). Due to the multiple negative consequences of childhood maltreatment, researchers are working to fully understand the effects that maltreatment has on the child's mental health and well-being.

Childhood Maltreatment and Nonsuicidal Self-Injury 
As many as $79 \%$ of children and youth that have reported a history of childhood maltreatment will engage in NSSI (Yates, 2009). The vast majority of studies examining the types of maltreatment and NSSI have hypothesized, and largely reported that sexual abuse as being significantly associated with the presence of NSSI (Bornovalova, Tull, Gratz, Levy, \& Lejuez, 2011; Glassman, Weierich, Hooley, Deliberto \& Nock, 2007; Madge et al., 2011; Yates, Carlson \& Egeland, 2008; Stewart, Baiden \& Theall-Honey, 2014). Specifically, in one study, children and youth who were sexually abused during childhood were four times more likely to inflict subsequent injury to themselves regardless of the intent of the self-harm (Noll, Horowitz, Bonanno, Trickett \& Putnam, 2003; Stewart, Baiden \& Theall-Honey, 2014). Other forms of childhood maltreatment have also been found to be associated with NSSI, although to a lesser extent. Childhood physical abuse has been associated with NSSI in some studies (Gratz, Conrad \& Roemer, 2002; Madge et al., 2011; Wachter et al., 2009) but not in others (Glassman et al., 2007; Nock \& Kessler, 2006). Even fewer studies have examined the effects of emotional abuse and neglect but what little evidence is available has suggested a significant association with NSSI (Busser \& Hackney, 2012; Glassman et al., 2007).

Another type of childhood maltreatment that has not been examined in association with NSSI is an exposure to intimate partner violence. Intimate partner violence has been found to occur more commonly than other types of maltreatment, as 1 in 3 children report witnessing their parents physically abusing each other during childhood, most commonly male on female violence (Litrownik, Newton, Hunter, English \& Everson, 2003). One reason intimate partner violence has not been examined further is that the vicarious trauma associated with exposure to intimate partner violence is not considered a form of child abuse in certain jurisdictions in Canada. Specifically, the Risk Assessment Model for Child Protection in Ontario (Ontario 
Association of Children's Aid Societies, 2000), which is a provincial strategy to protect children who have been abused, states that parenting behavior should be regarded as abusive if the child is present and physically suffers as a result. However, recent research has reflected that exposure to domestic violence is associated with a variety of mental health problems including depression, low self-esteem, Post Traumatic Stress Disorder (PTSD) symptoms, poor school performance and aggressive behaviours (Lourenço et al., 2013). Since exposure to intimate partner violence is considered to have such prominent effects on children, more research is needed to elucidate the effect of intimate partner violence on child and youth mental health.

\section{The Present Study}

Although there is increasing evidence that direct childhood maltreatment, particularly sexual abuse, is associated with engagement in NSSI, little research has focused on indirect forms of maltreatment in relation to NSSI. In the present study, we address this gap in the literature by examining whether exposure to direct and indirect forms of childhood maltreatment are associated with NSSI engagement among clinically referred children and youth. More specifically, we examined associations among sexual abuse, physical abuse, exposure to intimate partner violence (which has been neglected in the literature), and NSSI. We predicted that both direct and indirect forms of childhood maltreatment would demonstrate positive associations with NSSI engagement, underscoring the importance of developing targeted intervention strategies for children and youth with both direct and indirect child maltreatment histories.

\section{Methods}

\section{Participants}

This study was conducted through ten community mental health facilities across Ontario, Canada. There were 913 children between the ages of 4-18 years who took part in the assessment 
thus generating data that formed the basis of this study. Since children as young as 4 years of age are unlikely to engage in self injury with specific intent that would fit the definition of NSSI, the present study was restricted to examining children between the ages of 8-18 years. This age range also coincides with the most common age of onset for NSSI (Glenn \& Klonsky, 2009). The average age of the 747 children included in the analysis was 12.02 years $(S D=2.73)$. The majority of the children included in the analysis were male (68.4\%).

\section{Measures}

The measure used for the present study was the interRAI Child and Youth Mental Health Instrument (ChYMH; Stewart, Hirdes et al., 2015). The interRAI ChYMH assessment is based on a semi-structured interview format that supports the collection of a broad range of common problems encountered by children and youth with mental health problems. Domains include areas of concern including mental state indicators, substance use or excessive behaviour, strengths and resilience, cognition and executive functioning, independence of daily living, health conditions, family and social relations, stress and trauma, medication, prevention, service utilization, treatments, nutritional status, education, environmental assessment, diagnostic and other health related information.

Clinicians complete the instrument using all sources of information, including direct contact with the family and their child or youth, other service providers where possible (e.g., educators, mental health care clinicians). The interRAI ChYMH builds a comprehensive picture of individuals' strengths, needs, functioning, and areas of risk to inform care planning for clients with mental health needs.

The interRAI ChYMH comprises an assessment form with approximately 400 clinical elements covering medical, functional, psychological, social and environmental strengths, 
preferences and needs of school-age children, a variety of embedded scales that can be used for outcome measurement and 29 care-planning protocols identifying areas of imminent concern or risk (Stewart, Theall et al., 2015).

The ChYMH instrument is one of many instruments within an integrated assessment system developed through an international collaborative that is working to improve the quality of life for vulnerable persons. The ChYMH addresses many of the weaknesses found in other child and youth assessment tools, the most important being less reliance on self-report and more on evidence from file information and direct observation. Trained clinical assessors use information collected from the children and youth, their parents/guardians and any other available sources of information about the child's health, social life, education and safety (e.g., teacher reports, clinical charts, observations). It is used to help identify immediate needs, imminent risks and strengths of the child or youth.

Rigorous reliability and validity studies have been conducted across the family of interRAI instruments displaying strong psychometric properties for adults (Burrows, Morris, Simon, Hirdes, \& Phillips, 2000; Martin et al., 2007; Morris, Carpenter, Berg, \& Jones, 2000; Morris et al., 1997; Perlman \& Hirdes, 2008) as well as children and youth (Phillips et al., 2012; Stewart, Currie, Arbeau, Leschied \& Kerry, 2015; Stewart, Baiden \& Ninan, 2013; Stewart, Klassen \& Tohvner, 2015; Stewart, Tohvner \& Klassen, 2015).

Demographics. Age at time of the assessment was assessed in years, and sex was reported $(1=$ female, $2=$ male $)$.

Nonsuicidal Self-Injury. To assess for NSSI, children and youth were asked their most recent self-injurious attempt on a 5 -point Likert scale $(0=$ Never, $1=$ More than a year ago, $2=31$ days -1 year ago, 3=8-30 days ago, 4=4-7 days ago, 5=In the last 3 days). A dichotomous 
variable was created $(0=$ no NSSI, $1=$ history of NSSI). Furthermore, children/youth were asked if the intent of any self-injurious behaviour was to kill themselves. Children that indicated no intention of killing oneself were included as engaging in NSSI to ensure suicidal attempts were not included in this measurement. Thus, 60 participants with an unknown NSSI history were excluded (i.e., we could not determine whether participants with a suicidal attempt had a previous history of NSSI).

Childhood Maltreatment. This component of the assessment required assessors to examine whether the child had experienced physical abuse, sexual abuse, or witnessed domestic violence (as assessed by child/youth report, parent/guardian report, clinical charts, clinical observations), as well as indicate how recently this event occurred $(0=$ never, $1=$ more than $a$ year ago, $2=31$ days to a year ago, $3=8$ to 30 days ago, $4=4-7$ days ago, $5=$ in last 3 days). The presence of physical abuse $(0=n o, 1=y e s)$, sexual abuse $(0=n o, 1$ yes $)$ and witnessing sexual violence $(0=$ no, $1=y e s)$ were coded and included in the present study.

\section{Plan of Analysis}

Data was analyzed using Chi-square analyses, one way analysis of variance (ANOVA), and binary logistic regression. First, bivariate analyses using Chi-square tests were conducted to examine the associations between NSSI and the categorical variables of gender, sexual abuse, physical abuse, and exposure to intimate partner violence. An ANOVA was used to compare the mean age at the time of assessment for those who engaged in NSSI versus those who did not engage in NSSI. Third, binary logistic regression analysis was used to predict the presence/absence of NSSI from the predictors of age, gender, sexual abuse, physical abuse and exposure to intimate partner violence. The goodness-of-fit of the models was assessed by 
calculating the Hosmer-Lemeshow test with nonsignificant chi-square values indicating good fit (Hosmer-Lemeshow, 1989).

\section{Results}

Of the 747 children and youth, 177 (23.7\%) indicated that they had previously engaged in nonsuicidal self-injury and $510(68.3 \%)$. With respect to maltreatment, $73(9.8 \%)$ of children reported experiencing sexual abuse, $124(16.6 \%)$ of children reported experiencing physical abuse and $210(28.1 \%)$ reported exposure to intimate partner violence.

\section{Bivariate Analysis of Sample Characteristics by NSSI}

Results from Table 1 indicate the Chi-square test of association between NSSI and the categorical variables. At the bivariate level, a number of explanatory variables were found to be significant. There was a significant association between gender and NSSI $X^{2}(1)=12.598, p<$ .001 , sexual maltreatment and NSSI $X^{2}(1)=17.73, p<.001$, physical maltreatment and NSSI $X^{2}(1)=13.23, p<.001$, and exposure to intimate partner violence and NSSI $X^{2}(1)=15.29, p<$ .001 . In terms of the bivariate analysis between NSSI and age at time of assessment, age was found to be significantly associated with NSSI, $F(1)=38.87, p<.001$. The mean age of children and youth who engage in NSSI was 12.90 years of age whereas the mean age of those who did not engage in NSSI was 11.50 years of age, suggesting that older children were more likely to engage in NSSI than younger children.

\section{Multivariate Logistic Regression}

A binary logistic regression analysis was used to determine if sexual abuse, physical abuse and exposure to intimate partner violence would predict NSSI engagement. Age and sex were included in the model as covariates. A test of the full model against a constant-only model was statistically significant, indicating that the predictors as a set of variables, reliably 
distinguished between those that engaged in NSSI and those that did not $\left(\chi^{2}=62.878, \mathrm{p}<.001, d f\right.$ $=5)$. A Goodness model fit was evidenced by a nonstatistically Hosmer-Lemeshow test, $\chi^{2}$ $(n=687)=4.67, d f=8, p=.793$. The full model correctly classified $75.8 \%$ of the cases. Results suggested that of the three predictors in the model, exposure to intimate partner violence significantly predicted NSSI engagement (Wald $=4.703, d f=1, p=.030)$. The odds ratio for exposure to intimate partner violence indicated that, as experiences of exposure to intimate partner violence increased, children were 1.6 times more likely to engage in NSSI. The presence of direct forms of maltreatment (i.e., sexual abuse, physical abuse) was not associated with NSSI engagement in the multivariate model. Table 2 presents the results for the model including the regression coefficients, Wald statistics, odds ratio and 95\% confidence intervals for the odds ratios.

\section{Discussion}

Recent research suggests that exposure to direct forms of childhood maltreatment (e.g., physical abuse, sexual abuse) may be associated with increased risk for NSSI engagement. Little research, however, has examined the role of indirect forms of childhood maltreatment. To address this gap in the literature, and disentangle the potentail impact of direct and indirect forms of abuse, we examined whether physical abuse, sexual abuse, and exposure to intimate partner violence were associated with an increased risk for NSSI engagement among clinically referred children and youth. Consistent with previous research, we found that physical and sexual abuse were associated with NSSI engagement in our univariate analyses. It is interesting to note, however, that in our multivariate analyses only exposure to intimate partner violence was a significant predictor of NSSI engagement. Our findings underscore the importance of monitoring 
children and youth with exposure to domestic violence for risk for nonsuicidal self-injury, and incorporating targeted prevention efforts for high risk children and youth.

Consistent with previous research, we found that females and older children/youth were more likely to engage in NSSI than males and younger children/youth. Indeed, several studies have reflected that adolescent females are more likely to engage in NSSI than adolescent males (Bresin \& Schoenleber, 2015; Gandhi, Luyckx, Maitra, \& Claes, 2015; Sornberger, Heath, Toste, \& McLouth, 2012; Stewart, Baiden, Theall-Honey \& den Dunnen, 2014), although some studies suggest these differences are less pronounced in adulthood (Andover \& Gibb, 2010). We also found that the average age of participants in the NSSI group was 13, compared to participants without a history of NSSI (age $=11.5$ ). Given that the typical age of onset for NSSI is 12-15 years old (Glenn \& Klonsky, 2009), it is not surprising that older participants were at increased risk for NSSI, relative to younger children/youth.

Although physical and sexual abuse were associated with increased risk of NSSI engagement in the univariate analyses, only exposure to intimate partner violence emerged as a multivariate predictor of NSSI. There is evidence to suggest that children may engage in NSSI following witnessing violence as a social modelling of behaviour. Lemmey, McFarland, Wilson \& Malecha (2001) found that following witnessing intimate partner violence, children's mothers reported an increase in the child's aggressive behaviours (i.e., hitting, fighting). It could be that children engage in NSSI as a way to model the aggressive behaviours of their caregivers, but that these behaviors are self-directed. Research has also consistently shown that NSSI serves as a way to regulate aversive negative emotions (e.g., stress, anxiety, fear, sadness; see Klonsky, 2007 and Hamza \& Willoughby, 2015 for a review of this literature). Children witnessing 
intimate partner violence, therefore, may turn to NSSI as a form to regulate the overwhelming negative emotions associated with witnessing domestic violence.

Our finding that witnessing exposure to intimate partner violence was more strongly associated with NSSI engagement than physical and sexual abuse could be explained by the fact that physical and sexual abuse were experienced less frequently in the present sample than exposure to domestic violence (i.e., less power to find significant effects). In a recent study, however, researchers also found that exposure to domestic violence, as well as witnessing physical abuse of a sibling, led to more externalizing behaviours than the children who were directly physically abused (Renner, 2012). One explanation could be that children exposed to intimate partner violence may have more frequent abuse exposures (i.e., number of abuse episodes) than children who have experienced sexual or physical abuse, which could lead to more frequent episodes of distress. Researchers have proposed that over time, frequency of NSSI may be increased, as affective advantages are reinforced (Hamza \& Willoughby, 2015). Alternatively, an explanation as to why exposure to intimate partner violence was significant could lie in the ambiguous nature of loss and helplessness that is experienced when a child witnesses a caregiver being abused that is not experienced through direct victimization. Regardless, our findings highlight the important association between NSSI and exposure to domestic violence, which has been previously neglected in past research.

Future Research and Limitations

Despite the many strengths of the present study including a large sample size of clinically referred youth, and the use of a comprehensive multi-sourced assessment approach, the current study is not without limitations. The sample was limited to children and youth in 10 mental health facilities from Ontario, Canada. These facilities specialize in mental health issues for 
children and youth with complex and diverse mental health needs, which may not be generalizable to community samples. Moreover, only consenting parents/guardians of children and youth referred to the mental health facilities were included in this study which may not be representative of all referrals to those agencies.

\section{Implications and Conclusions}

Despite the limitations in the present study, the results have important implications for mental health research and practice. First, our findings are consistent with previous research that childhood maltreatment (both direct and indirect) are associated with increased risk for NSSI engagement among children and youth. Despite the fact that past research has not examined the impact of intimate partner violence on NSSI behaviors, the present study offers new evidence that domestic violence is another important risk factor for NSSI. Critically, our study lends support to the notion that even more subtle forms of childhood maltreatment can have damaging effects on a child's emotional well-being. Thus, clinicians should inquire about both direct and indirect forms of maltreatment at the time of intake, and explore if the child has experienced vicarious trauma via exposure to domestic violence. Moreover, our findings suggesting that treatment for children and youth with exposure to intimate partner violence, should also include preventative strategies for these at-risk youth, in an effort to circumvent NSSI engagement.

\section{Acknowledgements}


Jenna Armiento, the corresponding/primary author took on a leadership role in the conceptualization of the research work, as well as the analysis and interpretation of the data collected. Ms. Armiento was responsible for helping to write a draft of the work, and reviewed the final work prior to submission. Ms. Armiento agrees to be accountable for all aspects of the work, and Ms. Armiento had full access to all the data in the study and takes responsibility for the integrity of the data and the accuracy of the data analysis. Ms. Armiento has no conflicts of interest to disclose, but would like to acknowledge that she receipted graduate funding from the Social Science and Humanities Research Council and Ontario Graduate Scholarship program to conduct this research. Dr. Chloe Hamza was also involved in the conceptualization of the work, as well as the data analysis and interpretation. Dr. Hamza also assisted in writing up the work for publication, and reviewed the final work prior to submission. Dr. Hamza also agrees to take accountability for the accuracy of the work. Dr. Hamza has no conflicts of interest to disclose, but would like to acknowledge that she received postdoctoral funding from the Canadian Institutes of Health Research to conduct this research. Dr. Shannon Stewart had a major role in the design of the work, and the collection of data for the research. Dr. Stewart also contributed to the writing of the results for publication, and reviewed the work in its final iteration prior to submission. Dr. Stewart is also accountable for the integrity of the work. Dr. Stewart has no conflict of interests to disclose. Dr. Alan Leschied was involved in the conceptualization of the research, and assisted in the drafting and revising of the work. Dr. Leschied also reviewed the work prior to submission, and agrees to be accountable for the accuracy of the work. Dr. Leschied has no conflict of interests to disclose.

\section{References}


American Psychiatric Association (2013). Diagnostic and Statistical Manual of Mental Disorders (5th edition). Washington, DC.

Andover, M. S., Primack, J. M., Gibb, B. E., \& Pepper, C. M. (2010). An examination of nonsuicidal self-injury in men: do men differ from women in basic NSSI characteristics?. Archives of Suicide Research, 14(1), 79-88.

Asgeirsdottir, B. B., Sigfusdottir, I. D., Gudjonsson, G. H., \& Sigurdsson, J. F. (2011). Associations between sexual abuse and family conflict/violence, self-injurious behavior, and substance use: The mediating role of depressed mood and anger. Child Abuse \& Neglect, 35(3), 210-219. doi:http://dx.doi.org/10.1016/j.chiabu.2010.12.003

Bornovalova, M. a., Tull, M. T., Gratz, K. L., Levy, R., \& Lejuez, C. W. (2011). Extending models of deliberate self-harm and suicide attempts to substance users: Exploring the roles of childhood abuse, posttraumatic stress, and difficulties controlling impulsive behavior when distressed. Psychological Trauma: Theory, Research, Practice, and Policy, 3(4), 349-359. doi:10.1037/a0021579

Bresin, K., \& Schoenleber, M. (2015). Gender differences in the prevalence of nonsuicidal selfinjury: A meta-analysis. Clinical Psychology Review, 38, 55-64. doi:http://dx.doi.org/10.1016/j.cpr.2015.02.009

Buser, T. J., \& Hackney, H. (2012). Explanatory style as a mediator between childhood emotional abuse and nonsuicidal self-injury. Journal of Mental Health Counseling, 34(2), 154-169.

Burrows, A., Morris, J., Simon, S., Hirdes, J., \& Phillips, C. (2000). Development of a minimum data setbased depression rating scale for use in nursing homes. Age and Ageing, 29, 165-172.

Campbell, R., Greeson, M. R., Bybee, D., \& Raya, S. (2008). The co-occurrence of childhood sexual abuse, adult sexual assault, intimate partner violence, and sexual harassment: A 
meditational model of posttraumatic stress disorder and physicalhealth outcomes. Journal of Consulting \& Clinical Psychology, 76, 194-207.

Cerutti, R., Manca, M., Presaghi, F., \& Gratz, K. L. (2011). Prevalence and clinical correlates of deliberate self-harm among a community sample of Italian adolescents. Journal of Adolescence, 34(2), 337-47. doi:10.1016/j.adolescence.2010.04.004

Cloutier, P., Martin, J., Kennedy, A., Nixon, M. K., \& Muehlenkamp, J. J. (2010).

Characteristics and co-occurrence of adolescent non-suicidal self-injury and suicidal behaviours in pediatric emergency crisis services. Journal of Youth and Adolescence, 39(3), 259-269. doi:http://dx.doi.org/10.1007/s10964-009-9465-1

Gandhi, A., Luyckx, K., Maitra, S., \& Claes, L. (2015). Non-suicidal self-injury and identity distress in flemish adolescents: Exploring gender differences and mediational pathways. Personality and Individual Differences, 82, 215-220.

doi:http://dx.doi.org/10.1016/j.paid.2015.03.031

Giletta, M., Burk, W. J., Scholte, R. H. J., Engels, R. C. M. E., \& Prinstein, M. J. (2013). Direct and indirect peer socialization of adolescent nonsuicidal self-injury. Journal of Research on Adolescence, 23, 450-463.

Glassman, L. H., Weierich, M. R., Hooley, J. M., Deliberto, T. L., \& Nock, M. K. (2007). Child maltreatment, non-suicidal self-injury, and the mediating role of self-criticism. Behaviour Research and Therapy, 45(10), 2483-90. doi:10.1016/j.brat.2007.04.002

Glenn, C.R., \& Klonsky, E. (2009). Social context during nonsuicidal self-injury indicates suicide risk. Personality and Individual Differences, 46(1), 25-29.

DOI:10.1016/j.paid.2008.08,020 
Gratz, K. L., Conrad, S. D., \& Roemer, L. (2002). Risk factors for deliberate self-harm among college students. American Journal of Orthopsychiatry, 72(1), 128-140. doi:10.1037//0002-9432.72.1.128

Hamza, C. A., Stewart, S. L., \& Willoughby, T. (2012). Examining the link between nonsuicidal self-injury and suicidal behavior: A review of the literature and an integrated model. Clinical Psychology Review, 32, 482-495.

Hamza, C. A., \& Willoughby, T. (2015). Nonsuicidal self-injury and affect regulation: Recent findings from experimental and ecological momentary assessment studies. Journal of Clinical Psychology, 6, 561-574.

Heath, N. L., Toste, J. R., Nedecheva, T., \& Charlebois, A. (2008). An examination of nonsuicidal self-injury among college students. Journal of Mental Health Counseling, $30(2), 137-156$.

Hosmer, D. W., \& Lemeshow, S. (1989). Applied logistic regression. New York, NY: Wiley and Sons.

Klonsky, E. (2007). The functions of deliberate self-injury: A review of the evidence. Clinical Psychology Review, 27(2), 226-239. DOI:10.1016/j.cpr.2006.08.002

Lemmey, D., McFarlane, J., Wilson, P., \& Malecha, A. (2001). Intimate partner violence: Mothers' perspectives of effects on their children. MCN: The American Journal of Maternal/Child Nursing, 26(2), 98-103. doi:http://dx.doi.org/10.1097/00005721200103000-00009

Litrownik, A. J., Newton, R., Hunter, W. M., English, D., \& Everson, M. D. (2003). Exposure to family violence in young at-risk children: A longitudinal look at the effects of 
victimization and witnessed physical and psychological aggression. Journal of Family Violence, 18(1), 59-73. doi:http://dx.doi.org/10.1023/A:1021405515323

Lourenço, L. M., Baptista, M. N., Senra, L. X., Almeida, A. A., Basílio, C., \& de Castro Bhona, F. M. (2013). Consequences of exposure to domestic violence for children: A systematic review of the literature. Paidéia, 23(55), 263-271. doi:http://dx.doi.org/10.1590/198243272355201314

Madge, N., Hawton, K., McMahon, E. M., Corcoran, P., Leo, D., Wilde, E. J., . . Arensman, E. (2011). Psychological characteristics, stressful life events and deliberate self-harm: Findings from the child \& adolescent self-harm in europe (CASE) study. European Child \& Adolescent Psychiatry, 20(10), 499-508. doi:http://dx.doi.org/10.1007/s00787-0110210-4.

Martin, L. R., Hirdes, J. P., Fries, B. E. \& Smith, T. F. (2007). Development and psychometric properties of an assessment for persons with intellectual disability: The interRAI ID. Journal of Policy and Practice in Intellectual Disabilities, 4, 23-29.

Morris, J. N., Carpenter, I., Berg, K., \& Jones, R. N. (2000). Outcome measurement for use with home care clients. Canadian Journal of Aging, 19(S2), 87-105.

Morris, J. N., Fries, B. E., Steel, K., Ikegami, N., Bernabel, R., Carpenter, G. I. (1997). Comprehensive clinical assessment in community settings: Applicability of the MDSHC. Journal of the American Geriatrics Society, 45, 1017-1024.

Muehlenkamp, J. J., \& Gutierrez, P. M. (2004). An investigation of differences between selfinjurious behavior and suicide attempts a sample of adolescents. Suicide and LifeThreatening Behavior, 34, 12-23

Nixon, M. K., Cloutier, P. F., \& Aggarwal, S. (2002). Affect regulation and addictive aspects of repetitive self-injury in hospitalized adolescents. Journal of the American Academy of 
Child \& Adolescent Psychiatry, 41(11), 1333-1341.

doi:http://dx.doi.org/10.1097/00004583-200211000-00015

Nock, M. K., \& Kessler, R. C. (2006). Prevalence of and risk factors for suicide attempts versus suicide gestures: Analysis of the national comorbidity survey. Journal of Abnormal Psychology, 115(3), 616-623. doi:http://dx.doi.org/10.1037/0021-843X.115.3.616

Noll, J. G., Horowitz, L. A., Bonanno, G. A., Trickett, P. K., \& Putnam, F. W. (2003). Revictimization and self-harm in females who experienced childhood sexual abuse: Results from a prospective study. Journal of Interpersonal Violence, 18(12), 1452-1471. doi:http://dx.doi.org/10.1177/0886260503258035

Ontario Association of Children's Aid Societies. (2000). Risk assessment model for child protection in Ontario: Eligibility spectrum, risk assessment model for child protection in Ontario. Toronto, ON.

Perlman, C. \& Hirdes, J. (2008). The Aggressive Behavior Scale: A new scale to measure aggression based on the Minimum Data Set. Journal of the American Geriatrics Society, 56, 2298-2303.

Phillips, C. D., Patnaik, A., Moudouni, D. K., Naiser, E., Dyer, J. A., Hawes, C., Fourneir, C., Miller, T. R., \& Elliott, T. R. (2012). Summarizing activity limitations in children with chronic illnesses living in the community: A measurement study of scales using supplemented interRAI items. BMC Health Services Research, 12(19), 1-10.

Renner, L. M. (2012). Single Types of Family Violence Victimization and Externalizing Behaviors Among Children and Adolescents. Journal of Family Violence, 27(3), 177186. doi:10.1007/s10896-012-9421-9 
Ross, S., \& Heath, N. (2002). A study of the frequency of self-mutilation in a community sample of adolescents. Journal of Youth and Adolescence, 31(1), 67-77. doi:http://dx.doi.org/10.1023/A:1014089117419

Scott, K. M., McLaughlin, K. a, Smith, D. a R., \& Ellis, P. M. (2012). Childhood maltreatment and DSM-IV adult mental disorders: comparison of prospective and retrospective findings. The British Journal of Psychiatry: The Journal of Mental Science, 200(6), 46975. doi:10.1192/bjp.bp.111.103267

Sedlak, A. J., Mettenburg, J., Basena, M., Petta, I., McPherson, K., Greene, A., \& Li, S. (2010). Fourth national incidence study of child abuse and neglect (NIS-4):Report to congress.Washington, DC: US Department of Health and Human Services, Administration for Children and Families.

Sornberger, M. J., Heath, N. L., Toste, J. R., \& McLouth, R. (2012). Nonsuicidal self-injury and gender: Patterns of prevalence, methods, and locations among adolescents. Suicide and LifeThreatening Behavior, 42(3), 266-278. doi:http://dx.doi.org/10.1111/j.1943278X.2012.0088.x

Sternberg, K. J., Lamb, M. E., Greenbaum, C., Cicchetti, D., Dawud, S., Cortes, R. M., ... Lorey, F. (1993). Effects of Domestic Violence on Children's Behavior Problems and Depression, 29(1), 44-52.

Stewart, S.L., Baiden, P., Theall-Honey, L., \& den Dunnen, W. (2014). Deliberate self-harm among children in tertiary care residential treatment: Prevalence and correlates. Child and Youth Care Forum, 43(1), 63-81. DOI: 10.1007/s10566-013-9225-y 
Stewart, S. L, Baiden, P., \& Theall-Honey, L. A. (2014) Examining non-suicidal self-injury among adolescents with mental health needs. Archives of Suicide Research. Doi:10.1007/S 10566-013-9225-y

Stewart, S. L., Baiden, P., Ninan, A. (2013, November). The Aggressive Behavior Scale and predicting control interventions among youth. Poster presented at the 33rd Annual Meeting of the Canadian Academy of Child and Adolescent Psychiatry (CACAP). Vancouver Wall Centre Hotel, November 17th - 19th, 2013. Vancouver, BC, Canada.

Stewart, S. L., Currie, M., Arbeau, K., Leschied, A., \& Kerry, A. (2015). Assessment and Planning for Community and Custodial Services: The Application of interRAI Assessment in the Youth Justice System. In R. Corrado \& A. Leschied (Eds.), Serious and Violent Young Offenders and Youth Criminal Justice: A Canadian Perspective.

Stewart, S. L., \& Hirdes, J. P. (2015). Identifying mental health symptoms in children and youth in residential and inpatient care settings. Healthcare Management Forum. 1-7. DOI: $10.1177 / 0840470415581240$.

Stewart, S. L., Klassen, J., \& Tohvner, G. (August, 2015). The interRAI School Disruption Scale: A new scale to measure school engagement and disruption. Poster presented at the 2015 American Psychological Association Annual Meeting, Toronto, ON, Aug 6-9.

Stewart S. L., Hirdes, J. P., Curtin-Telegdi, N., Perlman, C., MacLeod, K., Ninan, A., Hall, M., Currie, M., Carson, S., Morris, J.N., Berg, K., Björkgren, M., Declercq, A., Finne-Soveri, H., Fries, B.E., Frijters, D., Gray, L., Henrard, J.C., Hirdes, J.P., James, M., Ljunggren, 
G., Meehan, B., Smith, T., Steel, K., Szczerbinska, K., Topinková, E. (2015). interRAI Child and Youth Mental Health (ChYMH) Assessment Form and User's Manual. Version 1. Washington, DC: interRAI.

Stewart, S. L., Leschied, A. W., den Dunnen, W., Zalmanowitz, S., \& Baiden, P. (2012). Treating mental health disorders for children in child welfare care: Evaluating the outcome literature. Child and Youth Care Forum, 42(2), 131-154.

Stewart, S.L., Theall, L.A., Morris, J.N., Berg, K., Björkgren, M., Declercq, A., Finne-Soveri, H., Fries, B.E., Frijters, D., Gray, L., Head, M., Hirdes, J.P., James, M., Ljunggren, G., Meehan, B., Smith, T., Steel, K., Szczerbinska, K., \& Topinková, E. (2015). interRAI Child and Youth Mental Health Collaborative Action Plans (CAPs) for use with the interRAI Child and Youth Mental Health (ChYMH) Assessment Instrument, Research Version 1 Standard Edition. Washington, DC: interRAI.

Stewart, S. L., Tohvner, G., \& Klassen, J. (July, 2015). The validation of the interRAI ChYMH Internalizing Subscale in Canadian Children and Youth. Poster presented at the International Society for the Study of Individual Differences Conference, London, ON.

Trocmé, N., Fallon, B., MacLaurin, B., Daciuk, J., Felstiner, C., Black, T., Tonmyr, L., ... \& Cloutier, R. (2010). Canadian incidence study of reported child abuse and neglect, 2008. Ottawa: Public Health Agency of Canada. 
Wachter, T., Murphy, S., Kennerley, H., \& Wachter, S. (2009). A preliminary study examining relationships between childhood maltreatment, dissociation, and self-injury in psychiatric outpatients. Journal of Trauma \& Dissociation : The Official Journal of the International Society for the Study of Dissociation (ISSD), 10(3), 261-75.

doi:10.1080/15299730902956770

Webster, L. (2013). Child maltreatment. Crisis counseling, intervention, and prevention in the schools (3rd ed.). (pp. 106-127) Routledge/Taylor \& Francis Group, New York, NY. Retrieved from http://search.proquest.com/docview/1697762298?accountid=15115

Wilson, H. W., Stover, C. S., \& Berkowitz, S. J. (2009). Research review: The relationship between childhood violence exposure and juvenile antisocial behavior: A meta-analytic review. Journal of Child Psychology and Psychiatry, 50(7), 769-779. doi:http://dx.doi.org/10.1111/j.1469-7610.2008.01974.x

Yates, T. M. (2009). Developmental pathways from child maltreatment to nonsuicidal selfinjury. (pp. 117-137) American Psychological Association, Washington, DC. doi:http://dx.doi.org/10.1037/11875-007

Yates, T. M., Carlson, E. a, \& Egeland, B. (2008). A prospective study of child maltreatment and self-injurious behavior in a community sample. Development and Psychopathology, 20(2), 651-71. doi:10.1017/S0954579408000321 


\begin{tabular}{lll} 
Variables NSSI No NSSI Chi square (sig) \\
\hline
\end{tabular}

Table 1. Chi square test results comparing NSSI versus no NSSI 


\begin{tabular}{lccc}
\hline & $\mathrm{n}(\%)$ & $\mathrm{n}(\%)$ & \\
\hline Gender & & & $12.598(<.001)$ \\
$\quad$ Male & $105(15.3 \%)$ & $375(54.6 \%)$ & \\
$\quad$ Female & $72(10.5 \%)$ & $135(19.7 \%)$ & \\
& & & $17.732(<.001)$ \\
Sexual Abuse & $28(14.7 \%)$ & $29(42.3 \%)$ & \\
$\quad$ Yes & $149(21.7 \%)$ & $481(70.0 \%)$ & \\
$\quad$ No & & & \\
& & & \\
Physical Abuse & $43(6.3 \%)$ & $65(9.5 \%)$ & \\
$\quad$ Yes & $134(19.5 \%)$ & $445(64.8 \%)$ & \\
$\quad$ No & & & \\
Exposure to Intimate Partner & & & \\
Violence & & & \\
$\quad$ Yes & $69(10.0 \%)$ & $121(17.6 \%)$ & \\
$\quad$ No & $108(15.7 \%)$ & $389(56.6 \%)$ & \\
\hline
\end{tabular}

Table 2. Logistic regression results predicting NSSI

\begin{tabular}{lccccc}
\hline \multicolumn{1}{c}{ Predictor } & $B$ & $\begin{array}{c}\text { Wald } \\
\text { Chi- } \\
\text { Square }\end{array}$ & $\begin{array}{c}\text { Odds } \\
\text { Ratio } \\
(\text { ExpB })\end{array}$ & $P$ value & $\begin{array}{c}\text { 95\% Confidence } \\
\text { Interval }\end{array}$ \\
\hline Age & .177 & 25.167 & 1.194 & .000 & {$[1.114,1.280]$} \\
Gender & .607 & 9.642 & 1.836 & .002 & {$[.371, .799]$} \\
Sexual abuse & .471 & 2.163 & 1.601 & .141 & {$[.333,1.169]$} \\
Physical Abuse & .306 & 1.295 & 1.358 & .255 & {$[.435,1.248]$} \\
$\begin{array}{l}\text { Exposure to } \\
\text { Intimate Partner }\end{array}$ & .468 & 4.703 & 1.596 & .030 & {$[1.046,2.435]$} \\
Violence & & & & & \\
\hline
\end{tabular}

